\title{
Difference between Vascularization Indexes of the Placenta in Severe Pre-eclampsia and Normal Pregnancy by Three-dimensional Power Doppler Ultrasound
}

\author{
${ }^{1}$ Wiku Andonotopo, ${ }^{2}$ Herman Kristanto, ${ }^{3}$ Julian Dewantiningrum, ${ }^{4}$ Besari Adi Pramono
}

\begin{abstract}
Aim: The object of this study was to analyze the vascularization index of three-dimensional (3D) power Doppler ultrasound (PDUS) of the placenta in severe pre-eclampsia compared with normal pregnancy conditions by vascular biopsy sampling sphere.
\end{abstract}

Subjects and methods: This study is a prospective longitudinal observational study on 80 pregnant women which divided into 2 groups: Group I (study group) were 40 pregnant women with severe pre-eclampsia, group II (control group) were 40 pregnant women without disorder. Variables examined in this study were vascular index $(\mathrm{VI})$, flow index $(\mathrm{FI})$ and vascular flow index (VFI) of the 3D-PD placental perfusion. Its correlation to gestational age in normal pregnancy compared with the condition of preeclampsia were obtained by taking multiple biopsy sampling vascular sphere. All pregnant women underwent 3D PD-US examination (single examination only), data volume recorded of the placenta allows for off-line analysis without the presence of the patient, thus allowing the data analysis done anywhere and anytime by observers for the comparative analysis of interobserver reliability.

Results: The placenta can be visualized perfectly in both of the study group and also the control group. Average Kappa value for the acquisition of placental vascularization index measurements with 3D PD-US was 0.72 (0.61-0.82), 0.73 (0.65-0.82) and 0.71 (0.61-0.81) for $\mathrm{VI}, \mathrm{FI}$ and $\mathrm{VFI}$ in the range of 20 to 38 weeks showed good interobserver reliability. All 3D power Doppler indices had a significant association with gestational age, with VI showed a less significant relationship $(r=0.207, p=0.0139)$ and $\mathrm{FI}$ has the most significant relationship $(r=0.582, p<0.001)$. FI index increased progressively with gestational age, while the VI index values indicate dispersion pattern and reached a plateau from week 30 onwards. Entering week 37 th, there was a decrease in the value of the index VI until the end of pregnancy. Meanwhile, VFI index appears to

\footnotetext{
${ }^{1-4}$ Lecturer

${ }^{1}$ Department of Obstetrics and Gynecology, Fetomaternal Division, Medical Faculty of Indonesia University, Tangerang General District Hospital, Banten, Indonesia

${ }^{2-4}$ Department of Obstetrics and Gynecology, Fetomaternal Division, Medical Faculty of Diponegoro University, Kariadi Hospital, Semarang, Indonesia

Corresponding Author: Wiku Andonotopo, Department of Obstetrics and Gynecology, Fetomaternal Division, Medical Faculty of Indonesia University, Tangerang General District Hospital, Banten, Indonesia, Phone: +62-81319409158, e-mail: drwiku@yahoo.com
}

resemble the pattern of a combination of both $\mathrm{VI}$ and $\mathrm{FI}$ index $(r=0.692, p<0.001)$.

Conclusion: All parameters of 3D power Doppler index was lower in the severe pre-eclampsia compared with normal pregnancy. 3D PD-US can be used to assess the vascularization of the placenta and the intensity of intra-placental blood flow. Placental vascular biopsy method is fairly efficient way to perform routine evaluations evolution of placental vascular branch during pregnancy.

Keywords: Pre-eclampsia, 3D power Doppler, Placental vascular biopsy, Vascular index.

How to cite this article: Andonotopo W, Kristanto H, Dewantiningrum J, Pramono BA. Difference between Vascularization Indexes of the Placenta in Severe Pre-eclampsia and Normal Pregnancy by Three-dimensional Power Doppler Ultrasound. Donald School J Ultrasound Obstet Gynecol 2014;8(4):329-335.

\section{Source of support: Nil}

Conflict of interest: None

\section{INTRODUCTION}

Severe pre-eclampsia is a pregnancy complication that causes increased mortality and morbidity in the mother and fetus. The etiology of pre-eclampsia which can not be clearly described so far lead to the development of various theories. ${ }^{1}$ One theory is the theory of trophoblast invasion is not perfect, uteroplacental ischemia by activation of maternal endothelial cells. Due to failure of trophoblast invasion of the spiral arteries spasm decidua are accompanied by endothelial damage, reduced vasodilator substances (prostacyclin and nitric oxide) and increased vasoconstrictor (such as thromboxane and endothelin) causes a decrease in blood flow to the placenta and uteroplacental insufficiency that can lead to impaired fetal growth, intrauterine asphyxia, fetal distress until death from lack of oxygen. ${ }^{2}$

The purpose of monitoring fetal well-being in patients with pre-eclampsia and gestational hypertension are predicting the risk of perinatal death. The risk of perinatal death in pregnancies will increase with uteroplacental insufficiency. Therefore, a techniques of three-dimensional power Doppler ultrasonography (3D-PD) was developed that allows the visualization and analysis of the characteristics of the blood vessels, such as vascular branching and caliber of blood vessels. ${ }^{3}$ In addition, some 3D ultrasound module allows to 
perform the analysis of the vascularization parameters as follows: vascularization index (VI), flow index (FI), vascularization flow index (VFI).

The three vascularization index presents a different analysis for semiquantitative examination of blood flow in the physical structure of the blood vessels. A number of studies concerning 3D-PD indices have been published in the last decade, especially in the field of obstetrics and gynecology. Several authors have shown that this index is correlated with blood flow in experimental models. ${ }^{4-7}$ Many researchers have proposed a range of reference indices obtained from a sample of the placenta during pregnancy and has also been evaluated whether the effects of complications that occur during pregnancy, such as miscarriage, maternal smoking, fetal growth retardation, and pre-eclampsia, associated with changes in the index 3D-PD placenta. ${ }^{8-16}$ However, this index is rarely used in clinical practice for several reasons, including the dependence of the index measuring the Doppler equipment settings, the determination of the volume of the sample size and even cardiac cycle. All of these limitations can potentially generate such a large deviation measure by different observations thereby reducing the accuracy of the method. ${ }^{17-23}$

The development of techniques that allow analysis of placental vascularization is essential for two reasons. First, it allows the visualization of abnormal development and insufficiency of placental vascular branching which is strongly associated with changes in fetal growth. ${ }^{24,25}$ Second, a decrease in vascular blood flow can occur earlier intraplacental before the increase in vascular resistance in the umbilical to detect the occurrence of this condition. ${ }^{25,26}$

A number of studies have evaluated the reliability of placental vascular assessment with 3D-PD ultrasound before 22 weeks of pregnancy. ${ }^{27}$ However, the final results of previous studies showed the contradictions and limitations in determining the definitive conclusion on the accuracy of the technique, which was the most important initial step before been tested clinically. ${ }^{28-31}$ On the other hand, placental biopsy samples sphere can be obtained at any gestational age, but have not found an agreement concerning the reliability of this method of research that has been published previously. ${ }^{32}$ It is expected that the method of biopsy samples sphere can represent the overall analysis of the placenta associated with some variability is correlated with the volume acquisition analysis, so the results of this technique can be applied in clinical applications.

\section{SUBJECTS AND METHODS}

\section{Subjects}

Subject were recruited from the outpatient care unit, Department of Obstetrics Kariadi Hospital Semarang and from Tangerang Hospital Banten in the period of December 2013-May 2014. This study was conducted with approval from the Health Research and Ethics Committee. Subjects were divided into two groups, each consisting of 40 patients: group I (study group) were pregnant women with severe pre-eclampsia and the second group is pregnant women with normal pregnancies as control. Inclusion criteria for group I is singleton pregnancies, gestational age $>20$ to 40 weeks, severe pre-eclampsia. Exclusion criteria for group I is the mother suffering from diabetes mellitus or other systemic disorders, antepartum hemorrhage, cord prolapse, congenital abnormalities in neonates. Criteria for group II (control group) is a normal pregnancy age $>20$ to 40 weeks where the mother has no medical disorder, not using certain drugs, no congenital abnormalities in the fetus. Indications for ultrasound exam in the control group were routine antenatal care with the 2D ultrasound, patients were asked to participate in the study using 3D ultrasound after receiving an explanation through informed consent. We hypothesized in this study that there was a decrease in vascularization index of 3D-PD placenta in pre-eclampsia compared to normal pregnancy conditions.

\section{Methods}

All pregnant women underwent 3D ultrasound examination (one examination only) to assess placental vascularization. Data volume of recorded placenta allows for off-line analysis without the presence of the patient, thus allowing the data analysis done anywhere and anytime by observers as well as a research assistant for the comparative analysis of interobserver reliability. Standardization of procedures done by selecting a constant sample volume sphere biopsy. In this study, the position of the placenta did not distinguished whether the placenta was on the anterior wall or posterior uterine wall. Five samples sphere location of the biopsy performed on each placenta, one center, two samples at locations opposite side and one in the center of the site and any peripheral sites (Fig. 1). Biopsy sampling sphere is always positioned so as to maintain a minimum distance of approximately $4 \mathrm{~mm}$ between insonation region, in both the chorionic plate and the basal plate area. Each sampling site was investigated using the 3D mode glass-body rendering, in which information is processed and refined colors combined to provide three-dimensional images. After capturing the volume, placental vascularization index histograms of data were analyzed using the tools of virtual organ computer-based VOCAL ${ }^{\mathrm{TM}}$ analysis (Fig. 2). Multivariate regression analysis with a correlation coefficient is used to determine the relationship between independent variables and the dependent variable. Accuracy is then illustrated 


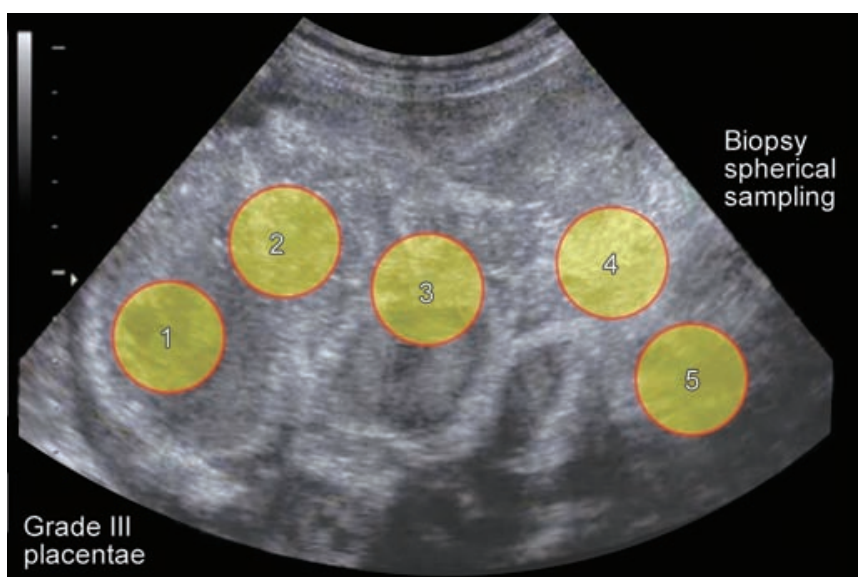

Fig. 1: Retrieval method demonstrated area on placental biopsy sampling sphere that looks the picture of vacuole-vacuole at the plate area of the placenta

by a scatter diagram, graph correlation and regression. The computer program Statistical 5.0 for Windows (Statsoft, 1995) was used for computing. The results were considered statistically significant when p-values were $<0.05$. Analyze-it 1.71 for Microsoft Excel (England UK, 2003) was used to compare bias of two different observers (interobserver reliability between observer WA and HK). The disagreement of both observers optionally measured in terms of bias analysis with $95 \%$ limits of agreement.

\section{Vascularization Index by 3D-PD Placental 'Sphere' Biopsy}

Three indices are automatically calculated by the VOCAL software and expressed as a parameter from 0 to 100 scale (Fig. 3): $:^{10}$

- Vascularization index, which is the ratio of the number of voxels in color compared to the amount of color and gray-scale voxels (voxel grayscale), which describes the overall perfusion.

- Vascularization flow index, which is the ratio of the sum of voxel intensities draw color to the overall amount of color and gray-scale voxel, which aimed to assess blood velocity in the same sample volume.

- Flow index, which is the ratio of the sum of the intensity of the colored voxels draw against the number of voxel colors, which reflect overall blood flow within the sample volume.

\section{RESULTS}

In the period of the study, as many as 40 women with pre-eclampsia met the study criteria. The placenta can be visualized perfectly in both of the study group and also the control group. Characteristics of the study group subjects are shown in Table 1. Mean gestational age was $31 \pm 5.5$ weeks (20-40) and $33 \pm 2.5$ weeks (20-38), respectively for normal pregnancy and pre-eclampsia.

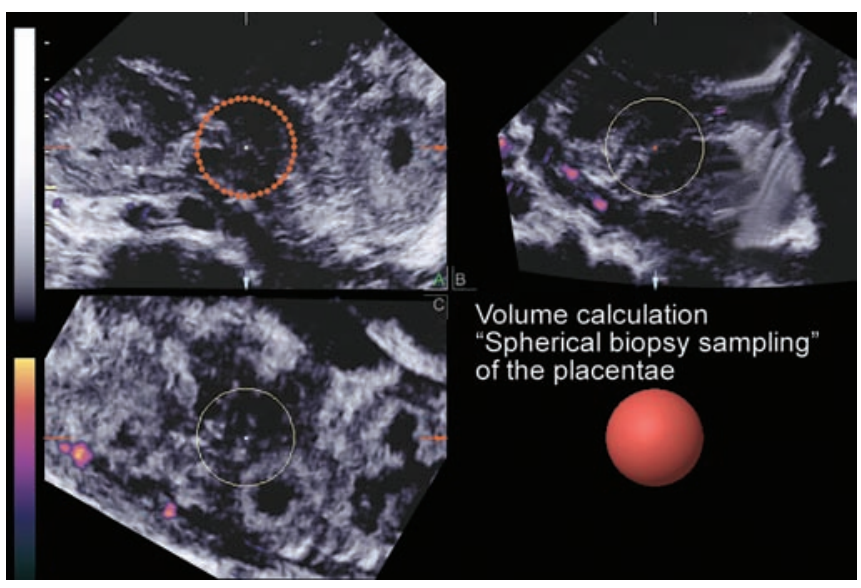

Fig. 2: The results of VOCAL calculation sphere biopsy sampling of the placenta at the plate making the first session and then continued until the fifth biopsy samples calculated entirely

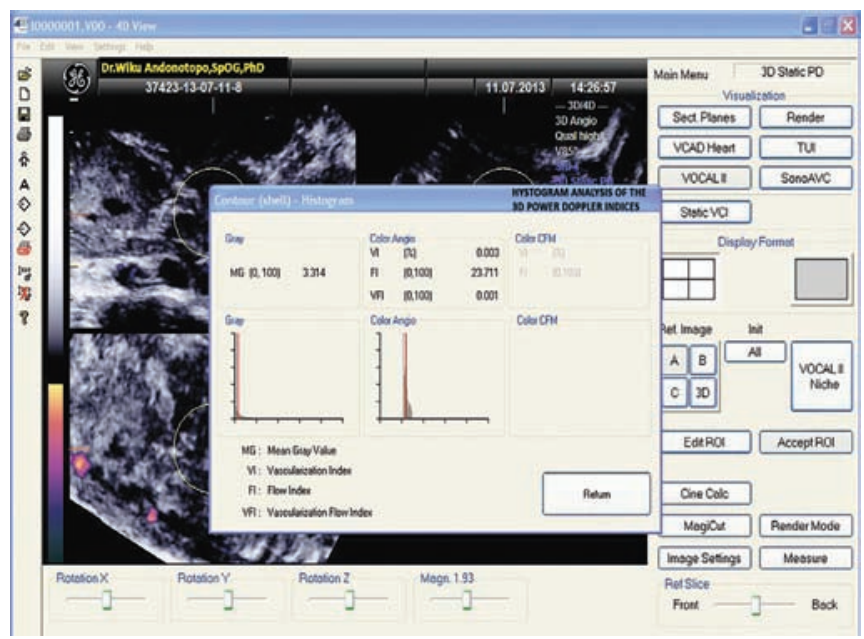

Fig. 3: The calculation of the histogram analysis of biopsy sphere calculation. The results calculation of $\mathrm{VI}, \mathrm{FI}$ and VFI displayed after biopsy volume calculated by VOCAL

Mean BMI was 24 (22-34) for normal pregnancy and 26 (19-38) for pre-eclampsia.

Vascularization index in group II VI showed normal values ranged from 3.88 to 14.1 in the second trimester of pregnancy, the third trimester of pregnancy, ranging between 14.4 and 15.5 , and showed a decrease in the index pregnancy through time. Vascular Flow Index in group II VFI showed normal values range between 1.002 and 4.338 in the second trimester of pregnancy, the third trimester of pregnancy ranged from 4.488 to 4.918 , and showed a decrease in the index pregnancy through time. Flow index in group II showed normal values FI ranged from 25.84 to 33.75 in the second trimester of pregnancy, the third trimester of pregnancy, ranging between 34.39 and 41.09 and did not show a decrease in the index pregnancy through time.

All 3D power Doppler indices had a significant association with gestational age, with VI showed a less significant relationship $(r=0.207, p=0.0139)$ (Fig. 4) and 


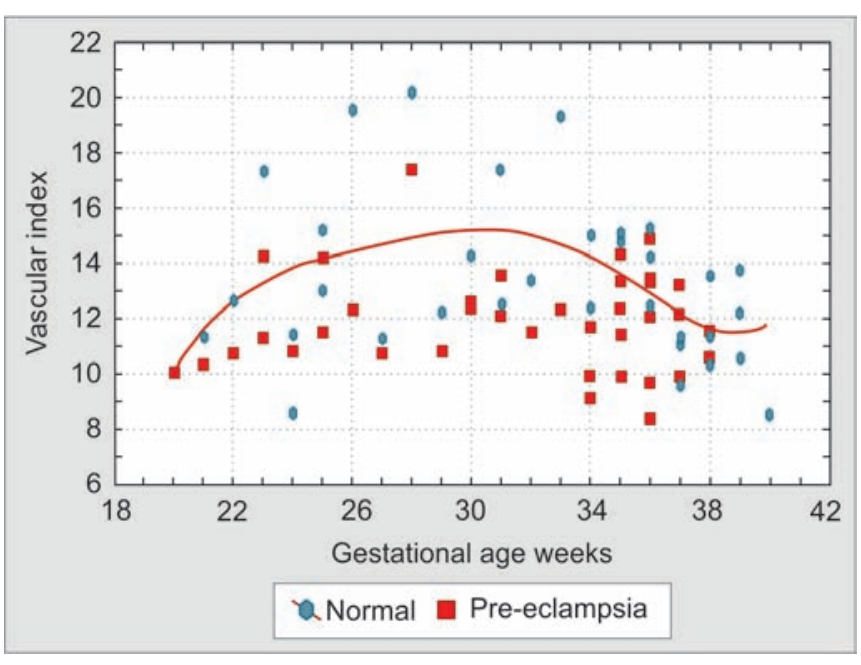

Fig. 4: Individual values $\mathrm{VI}$ on gestational age-related to severe pre-eclampsia cases and normal pregnancy $(y=-2.435 \times 21: 21$ $-0.04103 \times 2, r=0.207, p=0.0139$ )

FI has the most significant relationship $(\mathrm{r}=0.582, \mathrm{p}<0.001)$ (Fig. 5). FI index increased progressively with gestational age, while the VI index values indicate dispersion pattern and reached a plateau from week 30 onwards. Entering week 37th, there was a decrease in the value of the index VI until the end of pregnancy. Meanwhile, VFI index appears to resemble the pattern of a combination of both VI and FI index $(r=0.692, p<0.001)$ (Fig. 6).

Of the three parameters, only FI showed a normal distribution with small variability in cases of preeclampsia and normal pregnancy, while VI and VFI has a skewed distribution with high variability in both groups. All parameters (FI, VI and VFI) was lower in the severe pre-eclampsia compared with normal pregnancy (Table 2).

However, before testing the interest of this measurement method in daily clinical practice, it would need to be

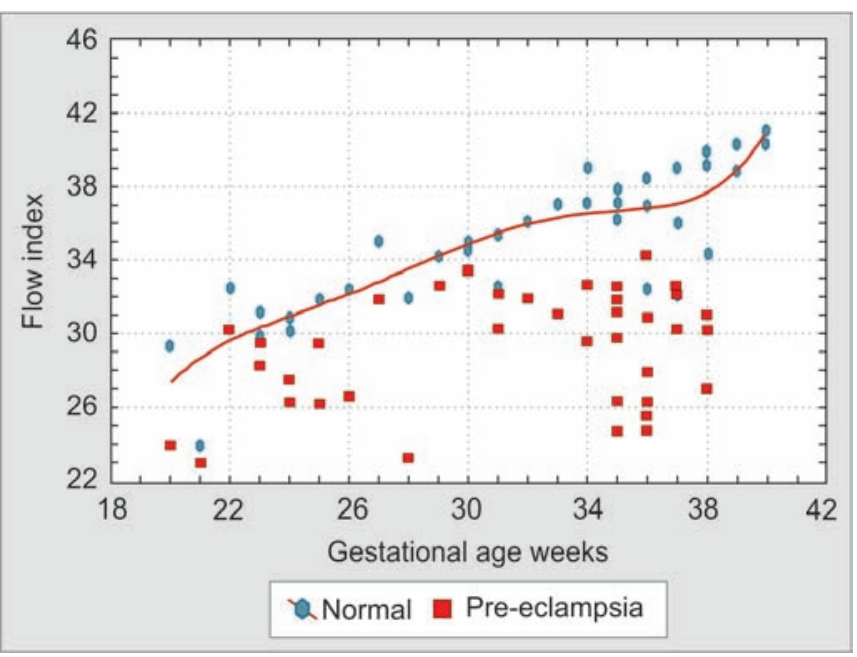

Fig. 5: Individual value $\mathrm{FI}$ in the case of pregnancy related to severe pre-eclampsia and normal pregnancy $(y=11.99+0.9505 \times$ $-0.006774 \times 2, r=0.582, p<0.001$ )

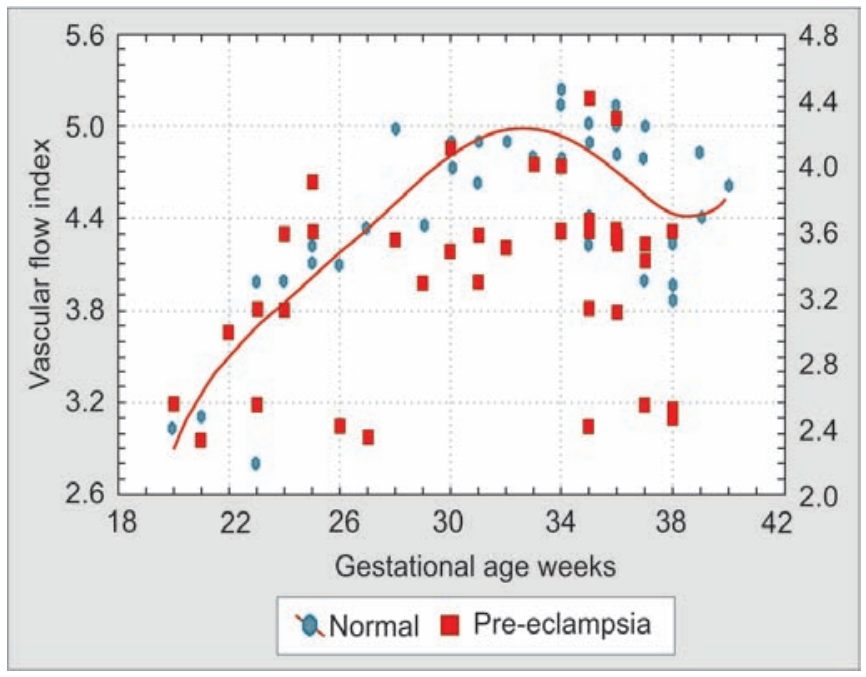

Fig. 6: Individual value VFI in the case of pregnancy related to severe pre-eclampsia and normal pregnancy $(y=-7805+0.766 x$ $-0.01158 \times 2, r=0.692, p<0.001)$

Table 1: Characteristics of study group compared with the control group (normal pregnancy)

\begin{tabular}{lll}
\hline Parameters & Pre-eclampsia & $\begin{array}{l}\text { Control group } \\
\text { (normal pregnancy) }\end{array}$ \\
\hline Age (years, mean \pm SD) & $33.5 \pm 3.5$ & $29.4 \pm 4.3$ \\
$\begin{array}{l}\text { Total \% primipara } \\
\text { Gestational age at examination } \\
\text { (weeks, mean } \pm \text { SD) }\end{array}$ & $15(37.5 \%)$ & $25(62.5 \%)$ \\
Body mass index (BMI) & $33 \pm 2.5$ & $31 \pm 5.5$ \\
\hline SD: Standard deviation & $26(19-38)$ & $24(22-34)$ \\
\hline
\end{tabular}

Table 2: Three-dimensional power Doppler index difference between severe pre-eclampsia and normal pregnancy

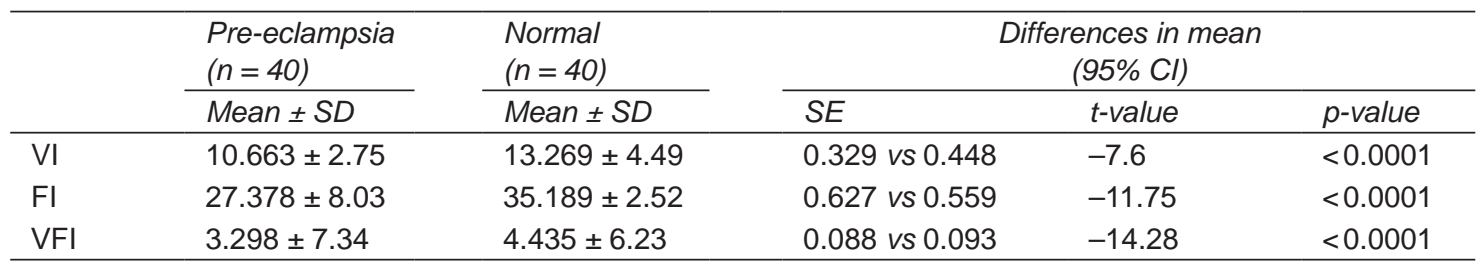

SD: Standard deviation; SE: Standard error; Cl: Confidence interval 
Table 3: Interobserver reliability assessment of placental vascularization by power Doppler 3D ultrasound

\begin{tabular}{ll}
\hline $\begin{array}{l}\text { Placental vascularization } \\
\text { index (measurement of } \\
\text { data sets by two observers) }\end{array}$ & $\begin{array}{l}\text { Interobserver reliability } \\
\text { intraclass correlation } \\
\text { coefficient (Kappa) }\end{array}$ \\
\hline $\mathrm{VI}$ & $\mathrm{K}=0.72, \mathrm{Cl} 95 \%,(0.61-0.82)$ \\
$\mathrm{FI}$ & $\mathrm{K}=0.73, \mathrm{Cl} 95 \%,(0.65-0.82)$ \\
$\mathrm{VFI}$ & $\mathrm{K}=0.71, \mathrm{Cl} 95 \%,(0.61-0.81)$ \\
\hline
\end{tabular}

Lowest coefficient was 0.71 for interobserver measurement of VFI

assessed interobserver reproducibility test of vascularity measurements by 3D PD-US (Table 3).

Each dataset is recorded on computer analyzed by two observers (researcher and research assistants) are 'off-line' on the computer. Reliability of measurement was assessed by Kappa test to estimate the level of agreement between measurements made by two observers. Data of placental vascularization from pre-eclampsia group were recorded in the form of a DICOM archive 3D PD-US is available in 40 datasets in total. Average Kappa value for the acquisition of placental vascularization index measurements with 3D PD-US was 0.72 (0.61-0.82), 0.73 (0.65-0.82) and 0.71 (0.61-0.81) for VI, FI and VFI in the range of 20 to 38 weeks showed substantial interobserver reliability. Kappa values confirms the high level of agreement between the measurements in all pregnancies. The amount of the deal value of marked guideline values $<0$ to indicate no agreement and 0 to 0.20 as slight, 0.21 to 0.40 as a draw, 0.41 to 0.60 as moderate, 0.61 to 0.80 as substantial, and 0.81 to 1 as an agreement almost perfect.

\section{DISCUSSION}

Placental vascularization biopsy technique with 3D PD-US is designed to obtain a representative sample of placental vascularization that allows the evaluation of placental vascular branching as a whole. ${ }^{10,30} 3 \mathrm{D}$ PD-US showed a high sensitivity because it is based on signal amplitude, not on the value of the average frequency. ${ }^{33}$ In addition, 3D PD-US showed no 'aliasing' effect and color mapping does not depend on the angle of insonation. ${ }^{33}$ However, artifacts can arise due to maternal or fetal movement. Some researchers recommend the acquisition of highspeed low resolution to avoid artifacts. ${ }^{10}$ Nevertheless, this method will not eliminate the artifacts as a whole. This can only be done by increasing the frequency of the pulsation power Doppler frequency of $900 \mathrm{~Hz}$. However, this technical modification is not recommended as it will likely eliminate the color signal sensitivity. ${ }^{10}$

This study has demonstrated substantial reproducibility in interobserver correlation observers 3D $\mathrm{PD}$ vascularity index. Intraclass correlation coefficients ranged from 0.71 to 0.73 for each index vascularization index. We conclude that the examination of placental vascularization index 3D PD-US can be applied in clinical practice as well as in the individual studies.

Three-dimensional PD-US allows complete and adequate study of placental vascular branching through the identification of the various branches of villous vessels of primary, secondary and tertiary, but also produces a quantitative evaluation of the vascularization of the placenta through the blood flow index and vascularization flow index applications. ${ }^{34-36}$ In this study, 3D PD-US vascularity index was significantly correlated with gestational age, although each of the indices showed different behavior. FI index increases linearly and progressively throughout pregnancy, VI index increased until week 30th, then hang on to the value of the plateau until week 37 th and then decreased. From this study, we found a large dispersion of the index value that describes why the coefficient of variation is greater.

Our results demonstrate conformity with previous studies that indices VI, FI, and VFI intraplacental increased with gestational age in normal pregnancy, but furthermore, we has described the sample volume applied and where the places are chosen to obtain a representative sample of placental vascularization. ${ }^{35}$

It is known that changes in umbilical artery Doppler blood flow revealed the occurrence of vascular pathological changes in placental villi branching at an advanced stage, so that the conventional Doppler blood flow measurements provide a low sensitivity as a diagnostic tool. ${ }^{37}$ Umbilical artery resistance increased only if $70 \%$ of the placental vessels become affected. ${ }^{10}$ Therefore, it can be assumed that the blood flow in the intraplacental vascular branches may be affected although in some cases the blood flow by Doppler umbilical still normal. ${ }^{38}$ It has been reported that the intraplacental vascular resistance greater than umbilical artery resistance levels associated with more complex pregnancy complications. ${ }^{10}$ Intraplacental vascular resistance obtained by measuring the power spectral Doppler is more sensitive and precede changes in the umbilical blood flow Doppler detection of inhibited fetal growth. ${ }^{38}$

It is known that the number of arterial branching villi were significantly reduced from the primary branches, secondary, tertiary branching until further order can no longer be detected in cases of intrauterine growth restriction. 3D PD-US method of placental vascular biopsy and the results of the evolution of the index of vascularization during normal pregnancy lasts meaningless in proving this hypothesis. ${ }^{38}$

The main result of this study is the difference in the parameters of placental vascularization index which was lower in the group of severe pre-eclampsia compared with normal pregnancy with no significant difference in most of the regions studied. The strength of this study is 
that confounding variables such as engine settings have been controlled first. Gestational age was recorded using linear regression. As we know that severe pre-eclampsia is part of a spectrum of disorders of the placenta, the data of this study are consistent with previous findings, where a decrease in the index parameter 3D vascularization and blood flow intensity is found in the case of severe intrauterine growth restriction. ${ }^{15}$

The reason for the high variability of the dispersion of data in this study could be due to a number of factors. Although the control measures were carried out, still allowing the emergence of research bias that occurs when deciding on which location samples were taken. Effect of sampling at different depths in the placenta may also account for variability. Although this research has been conducted on the adjustment of placental biopsy sample site location, depth insonation of power Doppler can not be adjusted automatically. From previous studies, it is known that within the three indices of vascularity, FI index is the most stable with a minimal amount of variability. ${ }^{15}$ The results of this study are consistent with previous studies with FI index values in this study showed a normal distribution in the dispersion of the group of severe pre-eclampsia and normal pregnancy in the fifth region of the placenta.

In a previous study using magnetic resonance imaging technology (MRI), there was clear trends of significantly reduced vascularization in the placenta from the basal plate to the chorionic plate in normal pregnancy. ${ }^{13}$ This observation would be consistent with the understanding that the blood flow will travel through the caliber of blood vessels which is relatively narrow (though there is a change) in the spiral arteries to achieve a relatively broad estuary at intervilli space. However, by using 3D PD-US, the gradient is not capable indicated. The reason for this has yet to be explained in detail. It is known that the basal plate has a large concentration of spiral arteries while the chorionic plate has a large concentration of blood vessels that originate from the fetus, therefore, good vascularization index parameter in the basal plate and chorionic plate may actually be similar and to confront the potential gradient vascularization.

\section{Limitations of Research}

The weakness of this study is that the index FI, VI and VFI did not translate into an easy concept to understand blood flow perfusion as a classic. Perfusion is measured in milliliters per minute per gram of tissue. While 3D power Doppler vascularity index reflects the vascularity and flow intensity, so in fact, this index does not measure tissue perfusion in the sense of the physiological. ${ }^{17}$ In addition, because of the power Doppler signal attenuation is highly dependent on the depth of insonation, vascularization index parameters may not be suitable for practical use in clinical obstetrics everyday. However, the measurement of placental vascularization index 3D PD-US once again is quite substantial. The interests of these methods for early diagnosis of vascular conditions and changes in fetal growth under conditions of severe pre-eclampsia are now open to learn.

\section{CONCLUSION}

All 3D power Doppler indices of placental vascularization has a significant relationship with gestational age. The most significant relationship was observed in the index FI and VI. FI index increased linearly associated with gestational age, while the VI index shows the dispersion value and constant in the plateau region entered the 30th week onwards, and then decreased at week 37th to the end of pregnancy. FI, VI and VFI of the placenta was significantly lower in the severe pre-eclampsia compared with normal pregnancy meant in all parts of the placenta. 3D PD-US can be used to assess the vascularization of the placenta and the intensity of intra-placental blood flow. Placental vascular biopsy method is fairly efficient way to perform routine evaluations evolution of placental vascular branch during pregnancy.

\section{REFERENCES}

1. Cunningham FG, Gant NF, Leveno KJ, Gilstrap III LC, Hauth JC, Wenstrom KD, editors. Pregnancy hypertension. In William Obstetrics: 23rd ed. USA:McGraw-Hill 2010:706-749.

2. Guimaraes Filho HA, da Costa LL, Araujo Junior E, Nardozza LM, Nowak PM, Moron AF, Mattar R, Pires CR. Placenta: angiogenesis and vascular assessment through three-dimensional power Doppler ultrasonography. Arch Gynecol Obstet 2008; 277:195-200.

3. Campbell S. Placental vasculature as visualized by 3D power Doppler angiography and 3D color Doppler imaging. Ultrasound Obstet Gynecol 2007;30:917-920.

4. Martins WP. Three-dimensional power Doppler: validity and reliability. Ultrasound Obstet Gynecol 2010;36:530-533.

5. Morel O, Pachy F, Chavatte-Palmer P, Bonneau M, Gayat E, Laigre P, Evain-Brion D, Tsatsaris V. Correlation between uteroplacental three-dimensional power Doppler indices and true uterine blood flow: evaluation in a pregnant sheep model. Ultrasound Obstet Gynecol 2010;36:635-640.

6. Raine-Fenning NJ, Nordin NM, Ramnarine KV, Campbell BK, Clewes JS, Perkins A, Johnson IR. Determining the relationship between three-dimensional power Doppler data and true blood flow characteristics: an in vitro flow phantom experiment. Ultrasound Obstet Gynecol 2008;32:540-550.

7. Jones NW, Hutchinson ES, Brownbill P, Crocker IP, Eccles D, Bugg GJ, Raine-Fenning NJ. In vitro dual perfusion of human placental lobules as a flow phantom to investigate the relationship between fetoplacental flow and quantitative 3D power Doppler angiography. Placenta 2009;30:130-135.

8. Noguchi J, Hata K, Tanaka H, Hata T. Placental vascular sonobiopsy using three-dimensional power Doppler ultrasound in normal and growth restricted fetuses. Placenta 2009;30:391-397.

9. Yu CH, Chang $\mathrm{CH}, \mathrm{Ko} \mathrm{HC}$, Chen WC, Chang FM. Assessment of placental fractional moving blood volume using 
quantitative three-dimensional power doppler ultrasound. Ultrasound Med Biol 2003;29:19-23.

10. Merce LT, Barco MJ, Bau S, Kupesic S, Kurjak A. Assessment of placental vascularization by three-dimensional power Doppler 'vascular biopsy' in normal pregnancies. Croat Med J 2005;46: 765-771.

11. Merce LT, Barco MJ, Alcazar JL, Sabatel R, TroyanoJ. Intervillous and uteroplacental circulation in normal early pregnancy and early pregnancy loss assessed by 3-dimensional power Doppler angiography. Am J Obstet Gynecol 2009;200:315.e1-8.

12. Rizzo G, Capponi A, Pietrolucci ME, Arduini D. Effects of maternal cigarette smoking on placental volume and vascularization measured by 3-dimensional power Doppler ultrasonography at $11+0$ to $13+6$ weeks of gestation. Am J Obstet Gynecol 2009;200: 415.e1-5.

13. Costa J, Rice H, Cardwell C, Hunter A, Ong S. An assessment of vascularity and flow intensity of the placenta in normal pregnancy and pre-eclampsia using three-dimensional ultrasound. J Matern Fetal Neonatal Med 2010;23:894-899.

14. Dar P, Gebb J, Reimers L, Bernstein PS, Chazotte C, Merkatz IR. First-trimester 3-dimensional power Doppler of the uteroplacental circulation space: a potential screening method for pre-eclampsia. Am J Obstet Gynecol 2010;203:238.e1-7.

15. Guiot C, Gaglioti P, Oberto M, Piccoli E, Rosato R, Todros T. Is three-dimensional power Doppler ultrasound useful in the assessment of placental perfusion in normal and growth restricted pregnancies? Ultrasound Obstet Gynecol 2008;31:171-176.

16. Odeh M, Ophir E, Maximovsky O, Grinin V, Bornstein J. Placental volume and three-dimensional power Doppler analysis in prediction of pre-eclampsia and small for gestational age between Week 11 and 13 weeks and 6 days of gestation. Prenat Diagn 2011; 31:367-371.

17. Martins WP, Raine-Fenning NJ, Ferriani RA, Nastri CO. Quantitative three-dimensional power Doppler angiography: a flow free phantom experiment to evaluate the relationship between color gain, depth and signal artifact. Ultrasound Obstet Gynecol 2010;35:361-368.

18. Raine-Fenning NJ, Nordin NM, Ramnarine KV, Campbell BK, Clewes JS, Perkins A, Johnson IR. Evaluation of the effect of machine settings on quantitative three-dimensional power Doppler angiography: an in vitro flow phantom experiment. Ultrasound Obstet Gynecol 2008;32:551-559.

19. Schulten-Wijman MJ, Struijk PC, Brezinka C, De Jong N, SteegersEA. Evaluation of volume vascularization index and flow index: a phantom study. Ultrasound Obstet Gynecol 2008;32:560-564.

20. Kudla MJ, Alcazar JL. Does sphere volume affect the performance of three-dimensional power Doppler virtual vascular sampling for predicting malignancy in vascularized solid or cystic-solid adnexal masses? Ultrasound Obstet Gynecol 2010;35:602-608.

21. de Paula CF, Ruano R, Campos JA, Zugaib M. Quantitative analysis of placental vasculature by three-dimensional power Doppler ultrasonography in normal pregnancies from 12 to 40 weeks of gestation. Placenta 2009;30:142-148.

22. Morel O, Tsatsaris V, Chavatte-Palmer P. First-trimester 3-dimensional power Doppler for the screening of preeclampsia: the analysis of a greater proportion of the uteroplacental unit might improve the accuracy of the method. Am J Obstet Gynecol 2011;204: e4-5; author reply e5-6.

23. Martins WP, Welsh AW, Lima JC, Nastri CO, Raine-Fenning NJ. The 'volumetric' pulsatility index as evaluated by spatiotemporal imaging correlation (STIC): a preliminary description of a novel technique, its application to the endometrium and an evaluation of its reproducibility. Ultrasound Med Biol 2011;37:2160-2168.

24. Bujold E, Effendi M, Girard M, Gouin K, Forest JC, Couturier B, Giguere Y. Reproducibility of first trimester three-dimensional placental measurements in the evaluation of early placental insufficiency. J Obstet Gynaecol Can 2009;31:1144-1148.

25. Guimaraes Filho HA, Mattar R, Araujo Junior E, da Costa LL, de Mello Junior CF, Nardozza LM, Nowak PM, Moron AF. Reproducibility of three-dimensional power Doppler placental vascular indices in pregnancies between 26 and 35 weeks. Arch Gynecol Obstet 2011;283:213-217.

26. Huster KM, Haas K, Schoenborn J, McVean D, Odibo AO. Reproducibility of placental volume and vasculature indices obtained by 3-dimensional power Doppler sonography. J Ultrasound Med 2010;29:911-916.

27. Jones NW, Raine-Fenning N, Mousa H, Bradley E, Bugg G. Evaluation of the intraobserver and interobserver reliability of data acquisition for three-dimensional power Doppler angiography of the whole placenta at 12 weeks gestation. Ultrasound Med Biol 2010;36:1405-1411.

28. Jones NW, Raine-Fenning NJ, Mousa HA, Bradley E, Bugg GJ. Evaluating the intra- and interobserver reliability of threedimensional ultrasound and power Doppler angiography (3D-PDA) for assessment of placental volume and vascularity in the second trimester of pregnancy. Ultrasound Med Biol 2011;37:376-385.

29. Lai PK, Wang YA, Welsh AW. Reproducibility of regional placental vascularity/perfusion measurement using 3D power Doppler. Ultrasound Obstet Gynecol 2010;36:202-209.

30. Merce LT, Barco MJ, Bau S. Reproducibility of the study of placental vascularization by three-dimensional power Doppler. J Perinat Med 2004;32:228-233.

31. Khan KS, Chien PF. Evaluation of a clinical test. I: assessment of reliability. BJOG 2001;108:562-567.

32. Martins WP, Nastri CO. Reproducibility of 3D power Doppler placental vascular indices. Arch Gynecol Obstet 2011;283:403-404

33. Dubiel M, Breborowicz GH, Ropacka M, Pietryga M, MaulikD, Gudmundsson S. Computer analysis of threedimensional power angiography images of foetal cerebral, lung and placental circulation in normal and high-risk pregnancy. Ultrasound Med Biol 2005;31:321-327.

34. Pretorius DH, Nelson TR, Baergen RN, Pai E, Cantrell C. Imaging of placental vasculature using three-dimensional ultrasound and color power Doppler: a preliminary study. Ultrasound Obstet Gynecol 1998;12:45-49.

35. $\mathrm{Yu} \mathrm{CH}$, Chang $\mathrm{CH}, \mathrm{Ko} \mathrm{HC}$, Chen WC, Chang FM. Assessment of placental fractional moving blood volume using quantitative three-dimensional power Doppler ultrasound. Ultrasound Med Biol 2003;29:19-23.

36. Kurjak A, Merce LT, Andonotopo W. 3D power Doppler in the study of fetal and maternal angiogenesis and vasculogenesis. The Ultrasound Review of Obstetrics and Gynecology 2006;6:1-19.

37. Yagel S, Anteby EY, Shen O, Cohen SM, Friedman Z, Achiron R. Placental blood flow measured by simultaneous multigate spectral Doppler imaging in pregnancies complicate by placental vascular abnormalities. Ultrasound Obstet Gynecol 1999;14:262-266.

38. Mu J, Kanzaki T, Tomimatsu T, Fukuda H, Fujii E, Takeuchi $\mathrm{H}$, et al. Investigation of intraplacental villous arteries by Doppler flow imaging in growth-restricted fetuses. Am J Obstet Gynecol 2002;186:297-302. 